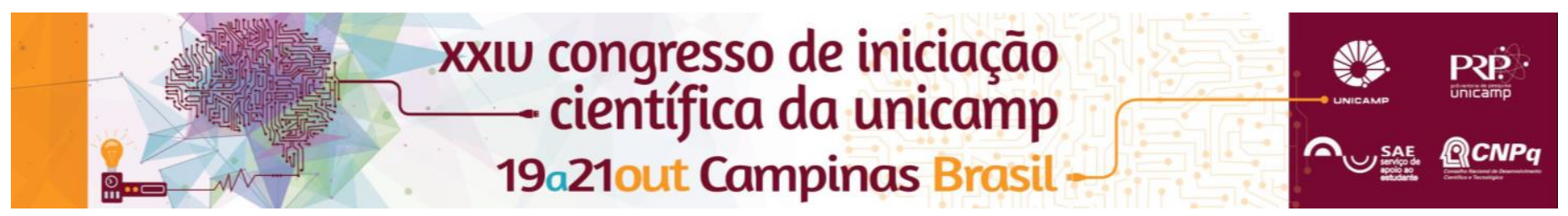

\title{
Degradação fotoeletroquímica do acetaminofeno utilizando eletrodos de TiO2 sob radiação solar
}

\author{
Andre C. Paiva*, Henrique Piva, Claudia Longo
}

\begin{abstract}
Resumo
Eletrodos de filme poroso de TiO2 foram utilizados para o tratamento de água contendo paracetamol (PCT) por fotocatálise heterogênea $(\mathrm{FH})$ sob irradiação com um simulador solar. Após preparar os eletrodos e investigar suas propriedades morfológicas e eletroquímicas, a atividade para degradação do fármaco foi investigada utilizando reatores contendo eletrodos com área de $7 \mathrm{~cm} 2$ e alíquotas de $25 \mathrm{~mL}$ de solução aquosa com $30 \mathrm{mg} / \mathrm{L}$ de PCT. Após irradiação por $4 \mathrm{~h}$ na presença do eletrodo de TiO2, na configuração $\mathrm{FH}$, observou-se degradação de $23 \%$ do PCT. Maior eficiência, $44 \%$ de degradação, foi observada quando um fio de Pt foi incluído como contra-eletrodo no sistema de $\mathrm{FH} e$ ambos os eletrodos foram conectados externamente a uma célula solar. A energia gerada pela célula solar tornou 0 processo de $\mathrm{FH}$ eletroquimicamente assistido e muito mais eficaz.
\end{abstract}

Palavras-chave:

Fotocatálise heterogênea - Paracetamol - TiO2

\section{Introdução}

A presença de fármacos, produtos de limpeza e outros contaminantes de preocupação emergente em corpos aquáticos tem sido cada vez mais estudada por pesquisadores. ${ }^{1}$ Diversos estudos relatam a detecção do acetaminofeno (ou paracetamol, PCT) em efluentes de estações de tratamento de esgoto, indicando que as metodologias utilizadas atualmente são ineficientes para a remoção deste fármaco, como também de outros poluentes. $^{2}$ Motivados em desenvolver métodos alternativos para tratamento de água, investigamos a atividade de eletrodos de $\mathrm{TiO}_{2}$ para remediação de água por fotocatálise heterogênea $(\mathrm{FH})$ e $\mathrm{FH}$ eletroquimicamente assistida (FHE). A atividade fotocatalítica é obtida quando o semicondutor é irradiado; ocorre então a promoção de um elétron para a banda de condução (BC), gerando uma lacuna na banda de valência (BV). Se a separação das cargas fotogeradas for eficiente, a lacuna pode reagir com moléculas de água ou com terminais $\mathrm{OH}$ da superfície do óxido e produzir radicais hidroxila $(\cdot \mathrm{OH})$, espécies altamente reativas que oxidam poluentes orgânicos. Em nosso Grupo de Pesquisa, desenvolvemos um sistema para tratamento de água que consiste de um fotoeletrodo de $\mathrm{TiO}_{2}$ e um contra-eletrodo (platina) que são conectados externamente a uma célula solar. A energia fornecida pela célula solar inibe a recombinação das cargas fotogerada, resultando em maior eficiência do processo de remediação de água através da oxidação de contaminantes. Esta estratégia já foi comprovada com êxito para o tratamento de solução aquosa contendo fenol, corantes e o hormônio estradiol ${ }^{3}$ nos motivando a investigar sua eficiência para a degradação do acetaminofeno dissolvido em água.

\section{Resultados e Discussão}

Os eletrodos foram preparados através da deposição de um filme poroso de partículas nanocristalinas de $\mathrm{TiO}_{2}$ em vidro revestido com $\mathrm{SnO}_{2}: \mathrm{F}$ (vidro $\mathrm{FTO}$ ). Análises da morfologia por microscopia eletrônica de varredura revelaram filmes uniformes de estrutura porosa e espessura entre 7 e $9 \mu \mathrm{m}$. Inicialmene avaliaram-se as propriedades eletroquímicas dos eletrodos em solução de PCT em eletrólito suporte $\left(\mathrm{Na}_{2} \mathrm{SO}_{4}\right)$. A seguir, os eletrodos de $\mathrm{TiO}_{2}\left(7 \mathrm{~cm}^{2}\right)$ foram utilizados na remediação de $25 \mathrm{~mL}$ de solução aquosa com $30 \mathrm{mg} / \mathrm{L}$ de PCT $\left(2,0.10^{-4} \mathrm{~mol} / \mathrm{L}\right)$ sob irradiação com simulador solar nas configurações de $\mathrm{FH}$ e FHE. A concentração remanescente de $\mathrm{PCT}$ foi determinada em intervalos de 60 min, utilizando cromatografia líquida de alta eficiência (CLAE). Para comparação, avaliaram-se soluções irradiadas na ausência do $\mathrm{TiO}_{2}$ (fotólise). A Tabela 1 apresenta os resultados ao final de $4 \mathrm{~h}$ de tratamento.

Tabela 1. Tratamento de solução aquosa contendo 30 $\mathrm{mg} / \mathrm{L}$ de paracetamol $\left(2,0.10^{-4} \mathrm{~mol} / \mathrm{L}\right)$ com eletrodo de $\mathrm{TiO}_{2}$ por $4 \mathrm{~h}$ sob irradiação com simulador solar: concentração final $\left(\mathrm{C}_{\mathrm{F}}\right)$, nº de mols de PCT degradados $(\Delta n)$ e porcentagem de degradação para as configurações Fotólise, FH e FHE

\begin{tabular}{|c|c|c|c|}
\hline Configuração & $\begin{array}{c}\mathbf{C}_{\mathbf{F}} \\
(\mathbf{m g} / \mathbf{L})\end{array}$ & $\begin{array}{c}\Delta \mathbf{n} \\
(\mu \mathrm{mol})\end{array}$ & $\begin{array}{c}\% \text { de } \\
\text { degradação }\end{array}$ \\
\hline Fotólise & 28,7 & 0,1 & 2 \\
\hline $\mathrm{FH}$ & 22,4 & 1,1 & 23 \\
\hline $\mathrm{FHE}$ & 16,3 & 2,1 & 44 \\
\hline
\end{tabular}

\section{Conclusões}

O desenvolvimento deste projeto tem apresentado diversos desafios, porém estamos obtendo resultados promissores para o desenvolvimento de um processo sustentável para tratamento de água utilizando eletrodos de $\mathrm{TiO}_{2}$ sob radiação solar.

\section{Agradecimentos}

Ao apoio técnico de Ricardo Pereira e à CAPES, CNPq, FAPESP e INOMAT pelo financiamento.

${ }^{1}$ Radjenovic, J.; Sirtori, C.; Petrovic, M.; Barceló, D.; Malato, S., Appl. Catal. B: Environ., 2009, 89, 255-264.

2 Joss, A.; Keller, E.; Alder, A.C.; Göbel, A.; McCardell, C.S.; Ternes, T.;

Siegnist, T., Water Res. 2005, 39, 3139.

3 Oliveira, H.G, Ferreira, LH.; Bertazolli, R., Longo, C.., Water Research 2015, 72, 305-314. 